\title{
Pavlovian conditioning and signaling: Higher order conditioning and transfer in rats
}

\author{
PHILIP COMPTON, DONNA WHITE, and DONALD ROBBINS \\ Emory University, Atlanta, Georgia 30322
}

\begin{abstract}
Five rats were trained to barpress for food and then a first-order Pavlovian task $\left(\mathrm{CS}_{1}\right.$-shock) was superimposed on this ongoing operant. Rapid suppression to $\mathrm{CS}_{1}$ was found. In the next phase, a second-order task $\left(\mathrm{CS}_{2}-\mathrm{CS}_{1}\right)$ was superimposed on the ongoing operant, followed by $\mathrm{CS}_{1}$ extinction and then by $\mathrm{CS}_{2}$ probe trials. Evidence of second-order conditioning was found even after $\mathrm{CS}_{1}$ extinction, as has been previously reported. In the final phase, a third signal $\left(\mathrm{CS}_{3}\right)$ was followed by $\mathrm{CS}_{1}$ and resulted in some suppression to $\mathrm{CS}_{3}$, although the response rate to $\mathrm{CS}_{1}$ during this phase was similar to that of the last day of $\mathrm{CS}_{1}$ extinction. The data suggest that when the $\mathrm{CS}_{1}$ was presented alone it resulted in behavior different from that when it followed a given signal.
\end{abstract}

One of the many phenomena Pavlov (1927) reported in his classic work was that of "higher order" conditioning. Specifically, he reported that a stimulus followed by food for a number of trials not only produces a conditioned salivary response, but also can be used as a "reinforcer" to establish conditioned salivation to some other neutral stimulus.

However, the literature on higher order conditioning has not been terribly successful, often revealing relatively low levels of conditioning. Recently, Rescorla (Rescorla, 1973; Rizley \& Rescorla, 1972) developed a procedure that yields extremely rapid and high levels of second-order conditioning. Rats are trained to barpress for food on a variable-interval (VI) schedule. Then a Pavlovian task is superimposed on this ongoing operant [e.g., a 10-sec flashing light $\left(\mathrm{CS}_{1}\right)$ that terminates with a $1 / 2$-sec 1-mA footshock], thus establishing first-order conditioning to the $\mathrm{CS}_{1}$ since the barpressing behavior essentially ceases during the $10-\mathrm{sec}$ flashing light. Subsequently, a 30 -sec tone $\left(\mathrm{CS}_{2}\right)$ is followed by the 10 -sec flashing light (the $\mathrm{CS}_{1}$ ), and the suppression ratio to the tone goes from .5 (no suppression) to near zero (total suppression) in four to eight trials. Rizley and Rescorla (1972) also demonstrated that, once established, second-order conditioning appears to become independent of the conditions necessary for its occurrence, since extinction of $\mathrm{CS}_{1}$ does not reduce the conditioning level of $\mathrm{CS}_{2}$ after second-order conditioning is established. Further, Rescorla (1973) reported another extremely clever study in which, after $\mathrm{CS}_{1}$ extinction, $\mathrm{CS}_{2}$ is used as the "reinforcer" to reestablish suppression to $\mathrm{CS}_{1}$. Rescorla (1973) points out that first- and second-order conditioning may reflect different independent associative processes.

This research was supported by Grant 5T01HD00208 from the National Institute of Child Health and Development. Requests for reprints should be sent to Donald Robbins, Department of Psychology, Emory University, Atlanta, Georgia 30322.
With regard to the nature of second-order conditioning, Shapiro, Sadler, and Mugg (1971) reported evidence of second-order conditioning using dogs in a salivary conditioning paradigm. However, the overall level was quite low and the acquisition function, instead of being negatively accelerated, was concave downward. That this latter finding was not the result of extinction of $\mathrm{CS}_{1}$ was demonstrated by the result that subsequent extinction of $\mathrm{CS}_{1}$ led to $0 \%$ salivation to $\mathrm{CS}_{1}$ but left the level of conditioning (although low) to the $\mathrm{CS}_{2}$ unaffected.

It may be that in Rescorla's studies he had not given enough trials to detect a concave downward function, plotting proportion conditioned response as a function of trials. Of course, if we are considering the suppression ratio as a dependent variable, the function would be concave upward, since acquisition when using the suppression ratio is a decreasing function. In the present study this possibility was explored.

\section{METHOD}

\section{Subjects and Apparatus}

The subjects were five female rats (Sprague-Dawley) about 100 days old at the start of the experiment. They were maintained throughout the experiment at $80 \%$ of their normal body weight.

The experimental chambers consisted of three identical operant boxes, $71 / 4 \times 12 \times 81 / 4$ in. $(18.4 \times 30.5 \times 21 \mathrm{~cm})$. Each chamber had a recessed food magazine in the center of the end wall, a bar 2 in. $(5.1 \mathrm{~cm})$ and $3 / 4$ in. $(1.9 \mathrm{~cm})$ above the magazine, and two panel lights, 6 in. $(15.2 \mathrm{~cm})$ apart, 2 in. $(5.1 \mathrm{~cm})$ above the bar. A $2,900-\mathrm{Hz}$ Sonalert was in the center of the end wall 5 in. $(12.7 \mathrm{~cm})$ above the food cup. The floor of the chamber was composed of $3 / 16-i n$. $(.48-\mathrm{cm})$ stainless steel rods spaced $3 / 4$ in. $(1.9 \mathrm{~cm})$ apart. This grid could be electrified through a relay-sequence scrambler from a high-voltage high-resistance shock source. The two end walls of the chamber were aluminum; the side walls and top were clear Plexiglas. Each box was enclosed in a sound- and light-resistant shell. Mounted in the center of the side wall of the outer shell was a $61 / 2-W$ light bulb and a speaker. Experimental events were controlled and recorded automatically by relay equipment located in an adjoing area. 


\section{Procedure}

In the first session, each rat was magazine trained manually with 45-mg Noyes food pellets. This session continued until the subject had emitted about 30 barpresses. Starting with the second experimental day, all sessions were $2 \mathrm{~h}$ long and the animal was placed on a VI schedule of reinforcement. For the first 4 days of training the schedule was VI $1 \mathrm{~min}$; throughout the remainder of the experiment a VI 2-min schedule was in effect.

After 22 days of VI training (18 days of VI $2 \mathrm{~min}$ ), two pretest sessions were given during which the stimuli subsequently to be used in conditioning were presented. During each session two presentations of each of what were to be $\mathrm{CS}_{1}, \mathrm{CS}_{2}$, and $\mathrm{CS}_{3}$ were superimposed on the barpressing behavior.

The next day began Phase 1 conditioning, designed to establish first-order conditioning to $C S_{1}$. During Phase 1 all five subjects received paired presentations of the $\mathrm{CS}_{1}$ and a $1-\mathrm{mA}$ $1 / 2$-sec footshock on a variable-time schedule; shock onset coincided with $\mathrm{CS}_{1}$ termination. Four such trials were given during each of the three 2-h sessions. Phase 2 was designed to produce second-order conditioning. A trial consisted of a 30-sec $\mathrm{CS}_{2}$ followed immediately by a 10 -sec $\mathrm{CS}_{1}$. Four such trials were administered on each of 3 days of Phase 2. The next day began Phase 3, which was an extinction phase. Each day four nonreinforced presentations of $\mathrm{CS}_{1}$ were superimposed on VI responding. The next three sessions assessed the conditioning of the second-order stimulus. During this session subjects continued to respond on the VI 2-min schedule. Superimposed upon this performance were four nonreinforced presentations of the 30-sec $\mathrm{CS}_{2}$. The final 3 days were a final conditioning phase of a 30 -sec $\mathrm{CS}_{3}$ followed by the 10 -sec $\mathrm{CS}_{1}$. Four such trials were given each day.

The specific stimuli used for $\mathrm{CS}_{1}, \mathrm{CS}_{2}$, and $\mathrm{CS}_{3}$ for each rat were: for one subject a flashing houselight $(2 / \mathrm{sec})$, a $2,900-\mathrm{Hz}$ tone, and continuous panel lights, which served as $\mathrm{CS}_{1}, \mathrm{CS}_{2}$, and $\mathrm{CS}_{3}$, respectively; for a second subject the $\mathrm{CS}_{1}$, $\mathrm{CS}_{2}$, and $\mathrm{CS}_{3}$ were continuous panel lights, a flashing houselight, and a 2,900- $\mathrm{Hz}$ tone, respectively; for a third subject a white noise click $(2 / \mathrm{sec})$, a $2,900-\mathrm{Hz}$ tone, and a flashing houselight served as the $\mathrm{CS}_{1}, \mathrm{CS}_{2}$, and $\mathrm{CS}_{3}$, respectively. The last two subjects both had the $2,900-\mathrm{Hz}$ tone as $\mathrm{CS}_{1}$, while one had the panel lights and the flashing houselight as $\mathrm{CS}_{2}$ and $\mathrm{CS}_{3}$, respectively, and the other had the flashing houselight and a white noise click as the $\mathrm{CS}_{2}$ and $\mathrm{CS}_{3}$, respectively.

To achieve comparability with prior work, one measure of conditioning used was the amount of suppression of barpressing produced by a stimulus presentation. This is typically done to attenuate the effects of individual differences in overall rate of responding and, as a result, the results are typically presented in terms of a suppression ratio. This ratio has the form $A /(A+B)$, where $A$ is the rate of responding during the CS and $B$ is the rate of responding in a comparable period prior to CS onset. Thus, a suppression of 0 indicates no responding during the CS $(100 \%$ conditioning), while one of .5 indicates similar rates of responding during the CS and pre-CS periods (little or no conditioning). In addition, to further examine overall effects of shock and subsequent second-order training, the mean response rates in the various phases were also a nalyzed.

\section{RESULTS AND DISCUSSION}

In Figure 1 is shown the mean suppression ratio and mean response rates for the various phases averaged across five subjects. The solid line represents the overall response rate per session for nonsignal periods. The overall rate was fairly stable prior to first-order conditioning (range .30-.34). During first-order conditioning, the only phase during which the subjects were shocked, the overall response rate for nonsignaled periods decreased (range .19-.27). However, during all other phases the rate returned to the baseline level (range .26-.33).

Rapid first-order conditioning can be seen in Sessions 23-25, with the rate to $\mathrm{CS}_{1}$ approaching zero. During the second-order conditioning phase, rapid conditioning can be seen but it appeared to dissipate over the 3 days of training (Sessions 26-28). At the end of second-order training the $\mathrm{CS}_{2}$ rate was still below the overall nonsignal rate, which by this time had recovered from the generalized suppressive effects of shock during the first-order phase.

First-order extinction never resulted in a .50 suppression ratio, although by the last day of extinction (Session 31) the $\mathrm{CS}_{1}$ response rate was very close to the overall nonsignal rate. The second-order probe trials revealed some suppression, although extinction seems evident. However, the $\mathrm{CS}_{2}$ rate was still somewhat below that of the nonsignal periods (Sessions 32-34).

In the last phase the $\mathrm{CS}_{1}$ response rate was quite variable, although it was below the overall nonsignal rate for Session 35, above it for Session 36, and slightly below for the last session (37). The $\mathrm{CS}_{3}$ response rate shows a concave upward function, terminating only slightly below the overall rate. The suppression ratio is similar, although more variable, still showing evidence of suppression during the final session.

The response rates were presented here to reveal a well-known fact: Although the use of suppression ratio takes into account momentary fluctuations in responding over time, it may "overact" to the momentary fluctuation. On the other hand, comparing the signal response rate to the overall nonsignal rate may give a clearer indication of the level of control of the signal. Since the overall nonsignal rate was fairly stable after the first-order phase, we can then examine the response rates to the various signals for evidence of control.

As a result some interesting findings emerge. Although the $\mathrm{CS}_{1}$ rate increases during extinction, the $\mathrm{CS}_{2}$ rate remains unchanged, that is, the $\mathrm{CS}_{2}$ rate during probe tests was about the same as it was at the end of second-order training. Further, although the $\mathrm{CS}_{1}$ rate in the final phase was quite variable, and on the average similar to that at the end of $\mathrm{CS}_{1}$ extinction, $\mathrm{CS}_{3}$ exhibited some control, as evidenced by the lower rate relative to nonsignal periods. Control animals that never received shock had been run in this study. Although they generally showed reduced responding to a signal when it first appeared, this effect disappeared rapidly, while for the five experimental subjects the signal control appeared to be longer lasting.

These data are at best suggestive regarding the shape of the second-order acquisition function. However, they do suggest an important distinction: that the $\mathrm{CS}_{1}$ when presented alone may result in behavior different from that when it is presented following a given signal. Thus, 


\section{Session Response Rote \\ (Non Signol Periods) \\ Suppression Rotio (SR) \\ CS, Response Rote (RR) $\bullet . . . \bullet$ \\ $\mathrm{CS}_{2}$ Response Rote (RR) $\longrightarrow$ \\ $\mathrm{CS}_{3}$ Response Rote (RR)}

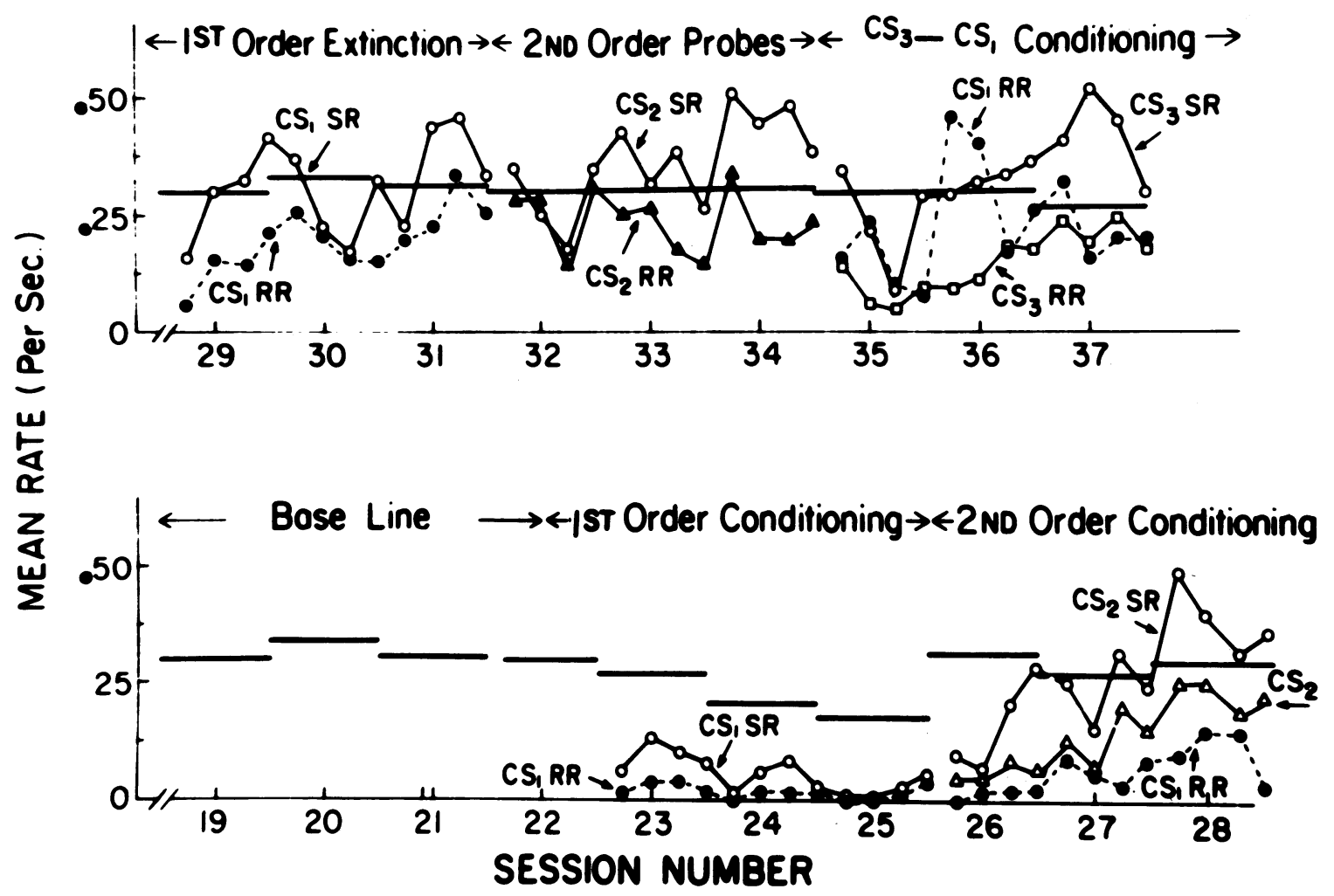

Figure 1. Mean rate (per second) as a function of session number. The four data points for each session represent the mean rate for each of the four signal trials in a session.

although $\mathrm{CS}_{1}$ during the final phase $\left(\mathrm{CS}_{3}-\mathrm{CS}_{1}\right.$ conditioning) did not lead to response rates very different from the last day of $\mathrm{CS}_{1}$ extinction, the signal preceding it, $\mathrm{CS}_{3}$, which had previously shown no differential responding, appeared to acquire suppressive tendencies, as $\mathrm{CS}_{1}$ had done during first-order conditioning.

\section{REFERENCES}

Pavlov, I. Conditioned reflexes (Trans. by G. V. Anrep). London: Oxford University Press, 1927.
Rescorla, R. A. Second-order conditioning, implications for theories of learning. In F. J. McGuigan \& D. B. Lumsden (Eds.), Contemporary approaches to conditioning and learning. Washington, D.C: Winston, 1973.

Rizley, R. C., \& Rescorla, R. A. Associations in secondorder conditioning and sensory preconditioning. Journal of Comparative and Physiological Psychology, 1972, 81, 1-11.

Shapiro, M. M., Sadler, E. W., \& Mugg, G. J. Compound stimulus effects during higher order salivary conditioning in dogs. Journal of Comparative and Physiological Psychology, 1971, 74, 222-226.

(Received for publication October 26, 1976.) 